\title{
China Private Enterprisese Top Management Team's Salary System Design- - based on the perspective of knowledge capital
}

\author{
Lin $\mathrm{Yu}$ \\ Department of Economic Management,Shanghaixingjian Business College , Yuanping Road 55,Jingan \\ District , Shanghai ,China \\ yulin0526@163.com
}

Keywords: China Private Enterprisese. T MT. Salary System Design

\begin{abstract}
The compensation of senior managers of the private enterprises in China is less competitive than that of foreign enterprises and large state-owned enterprises, leading to the loss of talents and the declining competitiveness of enterprises. This paper, based on the perspective of knowledge capital, the enterprise senior management team as intellectual capital to the enterprise investors view, knowledge capital property right, has designed internal equity and external competitiveness of salary standard to build a rational enterprise senior management personnel salary system.
\end{abstract}

\section{Theory Foundation of the Compensation Design of the TMT of the Private Enterprise}

China's private enterprises are implementing separate owner and operator of principal-agent management pattern, the principal-agent system exists incentive incompatibilities between owner and operator, which has brought a greater agency cost, moral risk and efficiency loss problem.The problems arise from the shortcomings of traditional property theory and the neglect of human self-interest. Therefore, the compensation design of the senior management team needs to be based on the economic hypothesis and the theory of modern property.

\subsection{The economic man assumes}

Rational economic man as a basic hypothesis of western economics, assumes that people are selfish, but in the face of two or more when the choice, always choose a better solution to himself. The ancestor of western economics Adam Smith thinks that person as long as do the "rational economic man" is ok, because the pursuit of self-interest maximization, everyone can become a sense of responsibility and enthusiasm, creative source of power ${ }^{[1]}$.

Based on a higher efficiency goal, the enterprise team form of human resource integration. Obviously, compared with individual, enterprise team behavior does help to bring a higher efficiency and more incremental revenue, but also the individual's contribution to the team effort become blurred.In this case, if the distribution of interests and individual contribution is not consistent, especially far below the marginal contribution of the individual, the individual's enthusiasm will be bruised. To offset compensation and contribution of asymmetry, especially in order to make up for the loss of expected reward, personal is bound by a negative way or take other selfish alternative measures, make the interest of the individual loss down to a minimum.

\subsection{Theory of intellectual capital property}

In the traditional view of property right theory, the investor of the financial capital - the owner of the enterprise, as the owner of the enterprise's net assets and the undertaker of the risk responsibility, has the residual claim and the surplus control right of the assets. This kind of responsibility and right relation has incentive property right motivation to the owner of enterprise, and it helps to encourage or compel the owner to continuously realize the improvement of enterprise's operation performance. But as the trustee of the business, due to the lack of property rights and related residual claims and residual control rights, there is a lack of incentive property rights motivation, but also the lack of internal power to improve business performance ${ }^{[2]}$.

The lack of correlation between financial capital theory of property rights incentive, the essence of the thought of human nature of self-interest should follow the role of re examining the operators, capital 
property research of manager of intellectual property rights, incentive mechanism through the combination of financial capital and knowledge capital property rights, incentive compatible mechanism between enterprises, under the principal-agent system shareholders, managers, employees, improve the enterprise management and efficient operation of good security.

\section{Principle of Compensation Design of Senior Management Team}

Capitalization of intellectual property, make intellectual capital as well as financial capital to the enterprise's surplus interests are allocated, the enterprise operator has a great incentive effect, also provides the operator management efficiency of the internal power source. However, it does not mean that the management performance of the enterprises will improve. So, when designing executive team pay, it must follow certain design principles.

\subsection{The principle of competition mechanism}

Under the principle of market economy, it is not only necessary to motivate the operator, but also to the benefit of control. Enterprises in the design of top management team compensation, must consider the enterprise in the market competition status, defeated in the competition, if enterprises management performance will not be able to achieve the expectations of shareholders, the stability of the operator's control will be threatened by serious, then the value of intellectual capital is not exist. So, in the introduction of competition mechanism under the control of the right incentives, the operator will be in the face of market competition, work hard, improve enterprise performance, and the more incentive competition in the market, operators in pursuit of property interests, will have to pay more efforts, the pursuit of higher efficiency ${ }^{[3]}$.

\subsection{The principle of surplus contribution}

The surplus contribution is the residual after-tax profit, which is that the after-tax profit of the enterprise exceeds the market average. On the static, residual contribution to market or industry averages for the minimum criterion, the dynamic, must be with the best level in the market or industry on narrowing the gap. The level of compensation for senior management teams should depend on the size of the remaining contribution. Without the rest, the knowledge capital of the senior management team cannot be paid. The larger the remaining contribution, or the smaller the gap in the market or industry's best level, the higher the proportion of senior management teams will share the remaining contributions ${ }^{[4]}$.

\subsection{The principle of Shared interests}

Senior management team pay design and the principle of sharing benefits. Is called the principle of benefit sharing, the remaining contributions don't all belong to the senior management team of intellectual capital, and shall be paid by the intellectual capital and financial capital share the surplus contribution, because for the rest of the contribution of creation, financial capital is indispensable. Leave the financial capital, the senior management team knowledge and management can not into the surplus profit after tax, so financial capital is of course to intellectual capital share the surplus contribution together.

\section{Idea of Compensation Design SeniorManagement Team}

\section{Structural Design}

According to the knowledge capital property right theory, the enterprise senior management team has a dual identity, one is the enterprise employee identity, second, as the owner of the intellectual capital. This dual identity decided to enterprise senior management team salary structure consists of two parts, one is unrelated to business performance pay part, 2 it is with the enterprise knowledge capital paid part of the performance.

\subsection{Employee compensation}

The employee compensation breakdown of the senior management team is split into two parts: basic pay and risk. 


\section{(1) Basic pay}

Management team members of the base salaries generally according to the employee's average salary as a benchmark, and no account of the differences of position, general with two times of average wage of employees will be the highest boundary.

\section{(2) Risk compensation}

The risk compensation of the members of a senior management team is related to the size of the position and the risk of responsibility. Risk compensation and additional compensation, and can include the position of position compensation risk depends on the size of the high and low and the risk of responsibility in the additional salary depends on the importance of the competent business. Risk compensation is based on base pay, multiplied by job risk factor or additive coefficient.

Although senior management team of employees do not directly linked with the management of the enterprise performance, but this part of the compensation is also changes with the change of the average worker pay. If the senior management team cannot through performance management, improve the economic benefits of enterprise growth is bound to affect the growth of the employee compensation, thus lead to the growth of the team members to employee compensation. And the higher the role of the team, the greater the role and the more important the executive, the greater the impact on pay. So the risk to the position of senior management team, management, business importance as the premise, the members of the average employee compensation and employee compensation, not only embodies the risks and rewards of symmetry principle, and has the leverage effect, through the average salary for employees, compensation benefit of management team and the overall interests of the general staff so that the enterprise be in harmony are an organic whole, forming a good incentive and restraint mechanisms of interaction ${ }^{[5]}$.

\subsection{Knowledge capital remuneration}

Enterprise senior management team of knowledge capital is the most important in the design of team pay remuneration, is based on the management of the enterprise performance out of the enterprise's after-tax profits to the enterprise senior management team of knowledge capital. This part of the compensation must be based on the management of the enterprise performance, through to the management team performance evaluation, and fully embody the principle of competitive advantage, and the rest of the principle of contribution and benefit sharing. Knowledge capital compensation design needs to solve two important problems: one is how to design the management performance evaluation index, the other is how the performance evaluation and the senior management team knowledge capital compensation. The following sections highlight these two issues.

\section{Design of the Performance Appraisal System}

A good management efficiency, must be established on the basis of sustainable competitive advantage, so in the design of the performance evaluation system, the need and the market or industry or the best average level, from two aspects of financial indicators and non-financial indicators design performance evaluation system.

\subsection{Performance evaluation index design}

\section{(1) financial indicators}

Financial indicators of performance evaluation index system should include the assets operation efficiency index, financial security index, cost index, profitability index, capital value index, the enterprise can choose according to their own business characteristics and operating situation was suitable for enterprises to improve their operation and management efficiency indicators, such as reflect the assets operation ability of asset sales, operating cash inflow rate, reflecting the ability of financial security operating cash flow index, suitable for operating cash flow ratio, equity ratio, liquidity ratio, quick-frozen ratio; The cost factor that reflects the cost control, the return on the profitability of the profitability, the net cash ratio; The return on equity and the return on capital of the value of the value of capital preservation.

(2) non-financial indicators

Non-financial indicators, enterprises can choose the management ability of senior management team, 
human capital, innovation potential, enterprise image lifting force index according to their own situation. Such as reflect the ability of senior management team to management decision-making ability, leadership ability, communication ability, innovation ability, learning ability, communication skills, team spirit, reflect the human capital in terms of security, employee sentiment index, senior technicians and management staff turnover, personnel mechanism, reflect the innovation potential patent index, the strength of $r \& d$, management innovation, and management of the enterprise image the customer satisfaction, the enterprise market image rating of lift growth rates, market share and customer list ${ }^{[6]}$.

\subsection{Performance evaluation index weight design}

It is impossible to make an accurate delineation of the weights of various indicators, but by analyzing them, we can find some common correlation features.

Financial and non-financial index weight design

International authoritative institutions in the critical evaluation of enterprise value, the non-financial indicators in the extremely important position, the reason is that for the success of an enterprise, people-oriented, customer first, innovation and adventure are indispensable. Non-financial indicators can form the core competence of the enterprise, maintain the competitive position of the advantage and win the trust of the customers, so that the enterprise wins the market. Therefore, in the evaluation of performance management of senior management team, must be the non-financial indicators, especially the customer satisfaction, employee sentiment index and innovation into focus, general non-financial indicators weight design is around $30 \%$.

Financial indicators are dominant in the performance evaluation index system, but in many financial indicators, $70 \%$ of the total weight needs to be allocated to each indicator. The discretion of the enterprise operating efficiency, not only make the enterprise resource configuration and operating efficiency at all levels and all the comprehensive reflection of, is also the enterprise financial goals and based on the premise of continuous business growth, so in the financial indicators, assets operation capacity index has a comprehensive, become the important index of top management team performance, need to account for the proportion of about $30 \%$. Other indicators, such as the value indicator, financial security indicators and cost control indicators, can be around $20 \%, 10 \%$ and $10 \%$.

\section{Share Design of the Remaining Contributions}

After the evaluation indexes and the weight, you need to share the contribution of the senior management team to participate in the residual ratio, and then calculate the operators can get the maximum residual contributions. It involves two problems, one is the management team of groups that the share proportion of residual contributions, another is the distribution of group contribution paid within the team.

\subsection{The management team's determination of the proportion of the remaining contributions}

The creation of the remaining contributions, is the result of the combination of financial capital and intellectual capital, before the remaining contributions allocations, financial capital and knowledge capital investment opportunity costs are compensated, the knowledge capital obtained the basic salary and risk compensation, financial capital is the equivalent of market or industry average capital returns. Based on this analysis, the residual contribution is at the best of $50 \%$ of the allocation between financial capital and intellectual capital.

The share proportion also is not absolute, different enterprise management performance can be further combined with the senior management team, or with the help of social capital value to the knowledge of the management team evaluation institutions and share proportion of residual contribution accurately determined. Or, in accordance with the market conditions of the professional manager, the shareholders and the senior management team shall negotiate and decide.

\subsection{Contribution compensation is determined by the allocation of proportion within the management team}

The above defined contribution is for the group as a whole, so the contribution will also need to be distributed within the team. Enterprise layer, vice President, general manager of the senior management team should include three levels managers and business managers, three levels of managers to each other, 
constitute a responsibility are inseparable, performance and benefits of coexisting organic whole. They each other although there are responsibility level and management division of labor, but for enterprise's overall business performance, any one aspect is indispensable and irreplaceable to each other. Therefore, it is reasonable to pay the remuneration to the management team for the "tri-three" distribution. "Three-thirds system" is a contribution to the total remuneration are divided into three parts, the layer of managers, business managers, vice President, general manager of each one-third, every level of contribution paid again depending on the degree of importance and risk business managers.

\section{Payment Method AND Payment Strategy Design}

\subsection{The method of payment}

\section{(1) cash payments}

The characteristics of cash payment are simple, small financial cost, and no change in the structure of the existing shareholding structure. But cash payments are flawed, and the incentive to cash is a thing of the past when senior managers get cash. With large amounts of cash, companies' ability to pay is likely to weaken.

\section{(2) stock payment}

To pay is the operator of a way of capitalization of intellectual property rights, on the basis of performance evaluation, the operator according to the value of intellectual capital get converted into performance shares in accordance with the relevant provisions of the price. The price that is used for the folded shares may be the market price of the stock, the net asset price per share, or the other price specified. According to the stock market prices, makes the company's market value with the enterprise operator's performance to unify, but because of the uncertainty of the market often unforeseen effects to the company. Adopt the way of book net assets can avoid the interference of various uncertain factors in the securities market, can accurately reflect the operator's contribution to the owners net assets value, can not only improve the interoperability, and has practicability to the listed and unlisted companies.

\section{(3) options payment}

Stock options, also calls the warrants, in fact, a kind of call options, refers to a right of the company awarded the incentive object, incentive object can be within the prescribed period of time (exercise) with pre-determined price (price) to buy a certain amount of current stock line (right) of the company. Stock option is a right, but not the obligation, holders in the stock price is lower than the "price" to give up this right, and therefore there is no risk of stock option holders. The right to a stock option also has time and quantity limits, and requires that the person be motivated to pay cash for the line.

\section{(4) other payments}

In addition to the above modes, there may be physical delivery, creditor's rights and other forms.

\subsection{Pay strategy}

\section{(1) the spot payment strategy}

Including prompt cash payment and spot stock payment, prompt payment is the payment to the operator during the current period. The prompt cash payment is the most realistic and immediate feeling for the operator, but it is the most transient of the incentive and restraint of the operator. If you pay a lot of cash directly, it will affect the capital flow of the enterprise and affect the development of the enterprise. Using stock payment at sight, although you can control the company's cash flow problems, but will affect the company's equity structure and stock market prices, this way is suitable for large amount of cash outflow and company cash or with a difficult situation is to raise equity to adjust the structure of the stock market. It is not easy for enterprises to pay for the payment of intellectual capital and occupational risk in the market.

\section{(2) deferred payment strategy}

Deferred payment is in the future on the basis of the specific performance of the operator to determine whether early pay issue, the issue of time, issued by the way, the time process to arrange a way, mainly includes the deferred cash payments and deferred pay two forms. This method combines the long-term interests of the operator with the long-term development strategy of the enterprise, and more fully embodies the consistency of the benefits and risks. There is a greater incentive efficiency and constraint 
effect for the operator.

\section{(3) options payment strategy}

Many companies now use options to pay for it, most of them using the concept of options, in essence or in terms of deferred payments. For the operator, the option to pay is the most incentive effect and the effect of restraint, the most to the company's long-term interests and the strategic target together with the interests of the operators, is knowledge capital value most utility to operator a payment method, suggested that enterprise will best option with deferred payment strategy used in combination.

\section{Conclusion}

In the enterprise to pay the remuneration paid to the senior management team has the following two parts: the first part is part of daily life security, ensure daily salary an operator shall use the cash payment at sight; Part in the second part is the incentive for operators professional risk and knowledge capital compensation, the strategy of combination of deferred payment and payment options, that part of the reward is mainly reflected on operator's incentive effect, more conducive to the long-term development of the enterprise and long-term interests and operator's personal career risks and benefits.

\section{References}

[1] YuLin, zhao shijun, lizhen. Research on the human capital of senior management team based on stock option incentive mechanism [J]. Enterprise economy, 2010

[2]Chen jiagui,Bu baofen, Huang qunhui. Incentives and constraints of state-owned enterprise operators [M]. Economic management press, 2001

[3]Bark G., Jensen M, Murphy K. Compensation and Incentives: Practice VS Theory[J]. The Journal of Finance, 1998(43):513-601.

[4]Garvey G., Grant S, King S. Talking Down the Firm: Short-term Market Manipulation and Optimal Management Compensation[J]. International Journal of Industrial Organization, 1998(16):465-606.

[5]Emilia C. Istrate; Emilia C. Istrate; Kadri Kallas; Roger R.Stough International journal of management and enterprise development, 2009.1.

[6] Dov Monderer; Moshe Tennenholtz Economic Theory, 2004 2.K-price auctions: Revenue inequalities, utility equivalence, and competition in auction design. 